\title{
Effects of COVID-19 Lockdown on Managing Diabetes Mellitus Among Sudanese Insulin Pump Users, A Cross-Sectional Study
}

\section{Esraa Hassan Salih}

University of Khartoum Faculty of Medicine

Khabab Abbasher Hussien Mohamed Ahmed ( $\square$ Khabab9722@gmail.com )

University of Khartoum Faculty of Medicine https://orcid.org/0000-0003-4608-5321

Omer Osman Osman Babiker

Sudan Childhood Diabetes Center

Malaz Tarig Abdalla Mohamed

University of Khartoum Faculty of Medicine

Mohammed Eltahier Abdalla Omer

University of Gadarif Faculty of Medicine and Health Science

Zeinab Mohammed Amara Salih

University of Khartoum Faculty of Medicine

\section{Research Article}

Keywords: Diabetes, COVID-19, Insulin pump, Sudan

Posted Date: January 10th, 2022

DOI: https://doi.org/10.21203/rs.3.rs-1221892/v1

License: (c) (i) This work is licensed under a Creative Commons Attribution 4.0 International License. Read Full License 


\section{Abstract \\ Background}

COVID-19 lockdown has affected diabetes management among the insulin pump users by changing their life style, affected their mental health, limited diabetes and insulin pump supplies and more difficult communication with the healthcare providers

\section{Objectives}

The aim of this research is to study the effects of COVID-19 lockdown on managing diabetes mellitus among Sudanese insulin pump users, Sudan (March-September 2020).

\section{Methodology:}

This is a descriptive cross-sectional community based study which was done in contact with Shimaa medical CO. LTD. 26 insulin pump users were chosen by total coverage and the data was collected throughout phone call interviews. All statistical analyses were performed using IBM SPSS Statistics software, version 20 .

\section{Results}

The mean age of 22 participants was $25.3 \pm 17.2$ years, and the majorities (63.6\%) were females. The average duration of diabetes was $6.9 \pm 3.9$ years, and the average duration of insulin pump use was $3 \pm 1$ years. Of the 22 patients (90.9\%) used glucometer for monitoring blood sugar. 9 (40.9\%) were less subjective to depression, 9 (40.9\%) had moderate susceptibility to have depression. 8 patients $(36.4 \%)$ reported weight gain, 12 patients $(54.5 \%)$ reported no weight changes, while 2 patients $(9.1 \%)$ reported weight loss. The level of physical activity decreased in 10 patients (45.5\%), and the dietary habits remained unchanged in $50 \%$. Moreover, participants who reported a decrease in physical activity levels were more likely to report weight gain $(P=0.004)$ compared with those who reported an increase in physical activity levels. Most of the patients have unchanged behaviors regarding experiencing hyper and hypoglycemic symptoms $45.5 \%, 72.7 \%$ respectively. Most of the patients have unchanged adherence to the insulin pump behaviors, carb counting (63.6\%), bolus wizard during mealtime (68.2\%), and bolus wizard for hyperglycemia correction (68.2\%), self-monitoring of blood glucose $(40.9 \%)$. (40.9\%) of the patients had scheduled phone call appointments, 5 patients $(22.7 \%)$ received virtual education (VE) from the insulin pump technician. 12 patients (54.5\%) reported difficulty obtaining at least one type of insulin pump supply.

\section{Conclusion}


COVID-19 lock down has led to the decrease in physical activity with unchanged dietary habits. Getting the insulin pump supplies was difficult for most of the patient's, and there was shortage and increase prices for diabetes care supplies. Telemedicine should be considered seriously to ease the communication between the patients and the health care providers.

\section{Introduction}

COVID-19 is a disease caused by SARS-Cov2, one of the Coronaviruses families, which started in December 2019 in Wuhan city, China. Coronaviruses are enveloped positive-strand RNA viruses that can infect both animals and humans. SARS-Cov2 is presented with fever, a nonproductive cough, sore throat, and myalgia, with dyspnea often not becoming a prominent feature until days 7-14 of the illness. The second phase is characterized by dyspnea and hypoxia. Respiratory distress syndrome is the final phase of the disease that may lead to death (1). The rapid spread of the virus worldwide led the WHO to announce it as an epidemic in March 2020 (2). In Sudan, the Federal Ministry of Health identified the primary cause of COVID-19 on 12 March 2020. On 14 March 2020, the government starts to execute measures to stop the spread of the virus, including reducing congestion in workplaces, closing schools, universities, closing the most bridges between the cities, and prohibit large public gatherings. From 8 July 2020, the government began to alleviate the lockdown restrictions in Khartoum State. The lockdown was lifted on 16 September (3).

Diabetes mellitus is a chronic disease that occurs when the pancreas is no longer able to make insulin (type 1) or when the body cannot get used to the insulin it produces (type 2) (4). Uncontrolled diabetes may lead to many complications. In almost all high-income countries, diabetes is a leading cause of chronic complications like cardiovascular diseases, eye problems, kidney problems, dental problems, neuropathy, and pregnancy complications (5). Acute complications like diabetic ketoacidosis, hyperglycemic hyperosmolar state, lactic acidosis, and hypoglycemia, considering diabetic ketoacidosis and hypoglycemia, are the most occurring complications in type 1 patients and hyperglycemic hyperosmolar state in type 2 patients (6). In 2019, approximately 54.8 million adults aged 20-79 years, or $12.8 \%$ of the Middle East and North Africa regional population during this age bracket, have diabetes. Sudan and Pakistan are the MENA region's countries that have the highest age-adjusted comparative diabetes prevalence (7). Taking medications like insulin for type 1 and tablets + or - insulin, maintaining a healthy diet, daily exercise, and psychological support are the most critical treatment components. People with type 1 diabetes and lots of people with type 2 got to take insulin to manage their blood sugar level by injecting it with a needle or pen or using an insulin pump.

The insulin pump is an advanced method that delivers insulin to the body. It works by secreting a tiny amount of insulin throughout the day (basal-bolus) and a meal bolus. The pump's flexibility by having multiple daily basal and temporary basal allows the basal-bolus adjustment in different situations (during exercise or when the person is ill). Some of the pumps are accompanied by a continuous glucose monitoring system. 
It is found that the insulin pump regimen is very useful in maintaining glycemic control by decreasing the episodes of hypoglycemia without affecting the incidence of diabetes ketoacidosis, which has been reduced. It also played a role in decreasing the micro and macrovascular complications, thus improving the user's life (8).

The results of curfew on a daily routine would have probably led to worsening of glucose control. Firstly, it has limited the maintenance of physical activities for people with diabetes. Secondly, restriction in food supplies during the lockdown would have compelled people with DM to vary their dietary habits that were earlier related to good glycemic control. Thirdly, procurement of anti-diabetic medications and glucose strips would be complex amid the continuing restrictions. Lastly, people with DM would not be able to visit their physicians for routine clinic follow-ups. This might lead to sustained periods of hyperglycemia, and probably frequent hypoglycemia episodes left unaddressed within the absence of in-clinic consultations. The COVID- 19 pandemic has adversely affected the psychological well-being of individuals everywhere on the planet. The constant anxiety of unknowingly contracting the virus, the strain of being locked down within rooms, and not having the pliability to satisfy their near and dear ones markedly affects the masses' psychological health (9). In Sudan the number of the insulin pump users is few because of the financial costs of the insulin pump and its supplies. During COVID-19 lockdown there was difficulty obtaining insulin pump supplies because of their availability was limited to one company in Khartoum, and the main bridges between the cities in Khartoum state and the interstate crossings were closed. Also, there were shortage and high prices of diabetes care supplies due to the effects of lockdown on the economic situations in Sudan. The restriction of movement during lockdown led to the indolence of diabetic patients which affects both their routine checkup and their life styles behaviors.

The insulin pump is almost unknown in Sudan, and up to our knowledge, very little researches have been carried out on the insulin pump. Because COVID-19 lockdown had many effects on managing diabetes, this paper evaluates the effects of COVID-19 lockdown on glycemic control, psychological part, change in lifestyle, access to diabetes clinic and supplies, co-morbidities, and the incidence of short-term complications among insulin pump users in Sudan. In this study we aimed to achieve both general and specific objectives:

\section{General objective:}

Effects of COVID-19 lockdown on managing diabetes mellitus among Sudanese insulin pump users.

\section{Specific objective:}

1. To assess the glycemic control on Sudanese insulin pump users during the lockdown.

2. To assess the psychological effect on Sudanese insulin pump users during the lockdown.

3. To assess the maintenance of diabetes routine care and the use of telemedicine on Sudanese insulin pump users during the lockdown.

4. To assess the change in lifestyle on Sudanese insulin pump users during the lockdown. 


\section{Materials And Methods}

Study Design: This is a descriptive cross-sectional study which was conducted in the republic of Sudan in the period March-September 2020.

Study area: Sudan is a country located in north-central Africa. Shima Medical CO.LTD is a Sudanese company with an international perspective, a leader in many therapeutic areas of healthcare, established in 2001 by Dr.Abdelrahman Khidir. It is the only company in Sudan that sells insulin pumps. The staff of the company includes pharmacists who work as diabetes educators and insulin pump technicians.

Study population: 26 Any Sudanese diabetic patient who is using an insulin pump during the lockdown in the study period were included in the study. 4 patients were excluded due to their refusal to participate.

\section{Inclusion criteria:}

1. Insulin pump users.

2. Willing to participate in the study.

3. Using an insulin pump during the lockdown.

\section{Exclusion criteria:}

1) Patients who stopped using insulin pumps before the lockdown.

2) Sudanese insulin pump users outside Sudan.

Sampling technique: Non probability sampling technique was used. Total coverage of all insulin pump users in Sudan during COVID-19 lockdown in the period of the study was done.

Sample size: Total coverage between March and September 2020 of 26 Sudanese diabetics who are using an insulin pump.

\section{Data collection:}

\section{Tool and technique:}

The data was collected by phone call interviews using a well-structured questionnaire. Most of it was taken from Sultan F. Magliah and his colleague's questionnaire in Saudi Arabia (10).

\section{Variables:}

The survey contained five parts:

1. Demographic data such as gender, age, residency, living situation, number of family members, the house ownership, monthly income, level of education, occupation, marital status, father's level of education, occupation, monthly income, and other income resources. 
2. Diabetes and insulin pump history, including $\mathrm{HbA} 1 \mathrm{c}$ before, during, and after lockdown and blood glucose monitoring.

3. Difficulties faced in maintaining routine care, including virtual appointments, virtual education, and availability of insulin pump-related supplies. Patients were asked if they had a scheduled phone appointment with anyone from the insulin pump team during the lockdown period, and whether the encounter was beneficial; whether they received virtual education by a diabetic educator or physician, the method of communication used, and whether the encounter was beneficial; which insulin pump supply they had difficulty obtaining if any, and whether they had to use multiple daily injections instead of the insulin pump due to lack of supplies.

4. Assessment of the impact of the lockdown on different self-management behaviors. Patients were asked to report any perceived weight change and to rate the following behaviors in comparison with the pre-lockdown period: the ability to follow a healthy diet, ability to maintain physical activity, and experience of hyperglycemia or hypoglycemia symptoms. Also, patients were asked to report any change in the adherence level to different insulin pump behaviors: carbohydrate counting, use of bolus wizard during mealtimes, use of bolus wizard for correction of hyperglycemia, and frequent self-monitoring of blood glucose for glucometer users.

5. Assessment of the psychological status during the lockdown. We used part of the Patient Health Questionnaire-9 (PHQ-9) to measure the possibility to get depression.

\section{Statistical data analysis:}

- Data entry: The data collected was entered into Microsoft excel database, and analyzed using IBM SPSS, Statistics software, version 20.

- Data analysis: Difference between groups was analyzed using the chi-squared test of Fisher's exact test for categorical data. A P-value $>0.05$ was considered statistically significant.

- Data presentation: Descriptive data were presented as mean (+_ standard deviation). Categorical variables were presented as frequencies and percentages. To determine associations between different self-management behavioral changes that occurred during the lockdown, we combined 'greatly increased' with 'somewhat increased', and 'greatly decreased' with 'somewhat decreased' ratings to facilitate interpretation.

\section{Ethical consideration:}

The research was conducted after approval was obtained from the ethical committee of the community medicine department, faculty of medicine, University of Khartoum. Informed consent was obtained from all participants before participation in the study. Their participation was voluntary. The withdrawal was allowed at any moment. High degree of confidentiality was preserved.

\section{Results}


Male represented $36 \%$, while females were $64 \%$. Table 1 summarizes the participants' Age. Participants' mean age was $25.3 \pm 17.2$ years.

\section{The occupational status of the insulin pump users}

Most of the patients were students 14 (63.6\%), 3 (13.6\%) were self-employed, 2 (9.1\%) were employed in governmental section, $1(4.5 \%)$ was employed in private section and $2(9.1 \%)$ were unemployed.

Duration of diabetes, duration of insulin pump using, blood glucose monitoring methods, associated comorbidities and chronic complications

The average duration of diabetes was $6.9 \pm 3.9$ years, and the average duration of insulin pump use was $3 \pm 1$ years.

The methods of blood glucose monitoring among the insulin pump users

Of the 22 patients $(90.9 \%)$ used a glucometer for monitoring blood sugar, 4 (18.2\%) used continuous glucose monitoring, and 13 (59.1) used a sensor-augmented insulin pump.

The associated co-morbidities among the insulin pump users

6 patients had associated co-morbidities 3 have hypertension (13.6\%), 1 has celiac disease (4.5\%) and 1 has atherosclerosis $(4.5 \%)$.

The percentage of chronic complications and among Sudanese insulin pump users

Of the 22 participants, 6 patients are having chronic complications; 2 patients have retinopathy, 2 patients have dental problems and 2 patients have neuropathy.

\section{Psychological status during lockdown}

Most of the participants 9 (40.9\%) were less subjective to depression, 9 (40.9\%) had moderate susceptibility to have depression, $1(4.5 \%)$ had moderately severe susceptibility to have depression, and 3 (13.6\%) had higher susceptibility to have depression.

\section{Self-management behaviors}

Tables 2 summarize the self-management behavioral changes during lockdown reported by the study participants.

\section{Weight changes}

During the lockdown, 8 patients (36.4\%) reported weight gain, 12 patients $(54.5 \%)$ reported no weight changes, while 2 patients $(9.1 \%)$ reported weight loss. 
During the lockdown, the level of physical activity decreased in 10 patients (45.5\%), remained unchanged in 9 patients $(40.9 \%)$, and increased in $3(13.6 \%)$. The ability to follow a healthy diet decreased in 7 patients (31.8\%), increased in 4 patients (18.1\%), and remained unchanged in 11 patients (50\%). Moreover, participants who reported a decrease in physical activity levels were more likely to report weight gain $(P=$ 0.004) compared with those who reported an increase in physical activity levels.

\section{The association between psychological effects and life style among the insulin pump users}

There is no significant association between the psychological effect of COVID-19 lockdown and the change in life style behaviors $P$-value $=0.34$.

\section{Symptoms of hyperglycemia and hypoglycemia}

Compared with the pre-lockdown period, 8 patients (36.3\%) experienced increased hyperglycemia symptoms, while $4(18.2 \%)$ and 10 (45.5\%) patients experienced decreased and unchanged symptoms, respectively. Additionally, 4 patients (18.1\%) experienced increased hypoglycemia symptoms, while 2 $(9.1 \%)$ and 16 patients $(72.7 \%)$ experienced decreased and unchanged symptoms, respectively.

\section{Adherence to insulin pump behaviors}

During the lockdown, most participants reported no change in adherence to carb counting (63.6\%), bolus wizard during mealtime (68.2\%), and bolus wizard for hyperglycemia correction (68.2\%). Of the 22 glucometer users, $6(27.2 \%)$ reported increased adherence to frequent self-monitoring of blood glucose, while $9(40.9 \%)$ reported no change in behavior.

\section{Maintaining diabetes care}

\section{Communication}

During the lockdown, 9 patients $(40.9 \%)$ had scheduled phone call appointments (PCA) with an insulin pump technician. All of them benefit from the appointment. In contrast, 13 patients (59.1\%) had no scheduled appointments during the lockdown period.

Moreover, 5 patients $(22.7 \%)$ received virtual education (VE) from a physician or diabetic educator during the lockdown. The virtual education session was considered beneficial by 4 patients $(80 \%)$ and moderately beneficial by one patient (20\%).

Methods of contact were phone calls (85.8\%), and video-assisted calls (28.6\%), and both video and texting (14.3\%).

\section{Insulin pump supplies}

During the lockdown, 12 patients (54.5\%) reported difficulty obtaining at least one type of insulin pump supply. The frequency of using multiple daily injections (insulin pen/syringe) for blood sugar control 
during lockdown due to lack of insulin pump resources was $3(25 \%)$.

\section{Discussion}

This research has observed the effects of COVID-19 lockdown on managing diabetes mellitus among 26 Sudanese insulin pump users. 22 of them have agreed to participate in this study and 4 refused to participate. 8 of the participants were males and 14 were females. The mean age of the participants was $25.3 \pm 17.2$. In a Saudi Arabian study, they measured the impact of the COVID-19 lockdown on different aspects of the lives of 70 T1DM patients above 18 years old who are using insulin pump therapy in Saudi Arabia. Although the Saudi's study was conducted properly, this paper didn't study the impact of the lockdown on type 2 diabetics who are using an insulin pump which was included in this study. The few numbers of insulin pump users in Sudan are because of the high price of the insulin pumps in Sudan which led some patients to return to use insulin injections.

Complete lockdown that started once the COVID-19 pandemic appeared and led to the minimization of the movement has negatively affected people with diabetes in many aspects like performing physical activity, healthy diet, getting diabetes care supplies, and reaching to health care professionals (21). Most of the patients in this study have an unchanged pattern regarding experiencing symptoms of hyper and hypoglycemia. Glycemic control has not been affected by lockdown, but rather than that it has been improved $(16,18)$. Another study demonstrated that hypoglycemic risk has increased in type 2 diabetics using insulin, antimalarial drugs, and sulfonylureas (14). The fear of getting infected has been a challenge for performing periodic checkups (22). Most of the patients could not do HbA1c tests during the pandemic.

This study has found that the dietary habits did not change for most of the patients. Physical activity is negatively affected by the fact that most of the patients become less active, which leads to the expression of hyperglycemic symptoms in some patients. In Saudi Arabia, Sultan F. Magliah and colleagues found that the dietary habits become worse during the lockdown in $41.5 \%$ of the patients, which is not similar to this study; on the other hand, physical activity was also decreased in $67.7 \%$, which is similar to what was found in this study (13). In Denmark, Dan Grabowski and his colleagues agreed with the Saudi's paper that lockdown has increased the consumption of unhealthy food and decreases the performance of exercise (22).

Another similar study was done in India that demonstrated that COVID-19 lockdown has $21 \%$ increase the level of Carbohydrates inside the meals and $23 \%$ increase in the number of snacks; also, the performance of physical activity has decreased by $42 \%$ (23). The results on dietary habits were not similar to a study done in Poland by Monika Gabria and her colleagues, which improved the dietary habits in $60 \%$ of the patients (17). Physical activity is an essential factor in improving glycemic control; as shown in a study done by Gianluca Tornese and his colleagues in Italy on type 1 diabetics who are using Hybrid Closed Loop, most of the patients performed regular physical activity, which appears to improve their glycemic control (20). A study was done which found that physical activity is affected by the lockdown in most 
patients; there is a decrease in $45.5 \%$ in performing physical activity compared to pre- lockdown while unchanged in $40.9 \%$ of the patients. This result was similar to María Belén Ruiz-Roso and her colleagues; they found that COVID-19, as expected, has decreased the time spent in performing physical exercise (24). The wide range of difference between the dietary habits results in this study (unchanged) and the other studies mentioned above (improved or worsen) most probably due to the unclear dietary schedule of the study population (even before lockdown) in this study (this could be due to the poor dietary culture in the developing countries), while physical activity is compatible with what mentioned in the literature and this is mostly due to the restriction of movement during lockdown and the psychological changes caused by restriction of physical activity.

The adherence to different insulin pump behaviors has been shown to improve glycemic control (25). This study reported no change in the adherence to carb counting (63.6\%), bolus wizard during mealtime (68.2\%), and bolus wizard for hyperglycemia correction (68.2\%). Of the 22 glucometer users, $9(40.9 \%)$ reported no change in behavior. This was similar to the paper done in Saudi Arabia, which demonstrated that there is no change in adherence to carb counting (69.2\%), bolus wizard during mealtime $(72.3 \%)$, and bolus wizard for hyperglycemia correction (61.5\%) (13). Due to the high prices and unavailability of diabetes care tools in Sudan, both type 1 and 2 diabetics minimize SMBG (26). In India, a study done by Rimesh Pal and colleagues found that youth with type 1 diabetes have minimized the number of SMBG and decrease the dose of insulin during lockdown either because of unavailability of strips or financial problems (27). Some of the participants have mentioned that lockdown has made them more aware to achieve better glycemic control. This may be due to the increase in free time.

Diabetes has a significantly bad effect on the economic situation for people living in Sudan (28). Getting diabetes supplies has been a significant challenge during lockdown because of the unavailability or high price of diabetes care supplies (Insulin and glucometer supplies). There were difficulties getting insulin pump supplies in $54.5 \%$ of the participants. Some of the participants kept a good amount of insulin pump supplies before lockdown, and 3 out of 12 who found difficulties obtaining insulin pump supplies reported multiple daily insulin injections using. In Jordan, lack of insulin and glucometer strips have led the families of diabetic children to minimize the insulin dose and the number of blood glucose measurements as mentioned by Rasha Odeh and her colleagues (15). As anticipated. This is because there is one company that sells insulin pump supplies located in Khartoum city, and the main bridges between the cities in Khartoum state and the interstate crossings were closed.

Telemedicine that was been launched in Sudan in 2005 has provided an excellent platform and a solution for communication with health care providers (29). It has been an essential factor in obtaining better glycemic control (19). In this study, most of the patients have no scheduled virtual appointments (59.1\%). In Saudi Arabia, $40 \%$ of the participants have made a scheduled phone call with their physician; almost all have benefited from it (13). In Italy, Federico Boscari and colleagues found that telemedicine has improved glycemic control in type 1 diabetics, the differences from what was mentioned previously (higher) mostly and this study is due to the absence of the culture of telemedicine and medical networking consultation in third world countries.

Page 10/16 
Virtual education has been an essential factor in increasing patients' awareness to obtain glycemic control in COVID-19 lockdown. 40.9\% reported they scheduled virtual appointments with the insulin pump technician because they have expressed some technical problem with their insulin pump. Most patients reported that they do not follow up with a physician or diabetes educator during phone interviews. In Saudi Arabia, 24 patients (36.9\%) received virtual education from a physician or diabetic educator during the lockdown. The virtual education session was considered beneficial by 23 patients $(95.8 \%)$ and nonbeneficial by 1 patient (4.2\%). The difference between the Saudi's study and this study is that most of the virtual educational session is about the insulin pump not involving sessions regarding diabetes. Some patients reported a lack of diabetes nutritional knowledge.

COVID-19 lockdown has a significant effect on the psychological aspect, which adversely results in poor management of diabetes (30). $13.6 \%$ of the participants were more vulnerable to depression, and this affected their glycemic control (HbA1c increased during lockdown compared to pre-lockdown, experienced fluctuation of hyper and hypoglycemic symptoms). According to the study that was done In Italy on 48 adult type 1 diabetict patients (18.7\% of them were pump users), it reported that half of the participants were at risk of mild psychological distress during the lockdown, as measured by the General Health Questionnaire-12 (11). In contrast, a Saudi study including 394 patients with type 2 diabetes reported that the COVID-19 lockdown had minimal impact on psychological health as measured by the Kessler Psychological Distress Scale (12). Finally, a study involving 1160 Saudi adults from the general population reported that $28.3 \%, 24 \%$, and $22.3 \%$ of the participants experienced moderate to severe depressive, anxiety, and stress symptoms, respectively, as assessed by the Depression, Anxiety, and Stress Scale at the beginning of the pandemic. The psychological disturbance among diabetic patients during lockdown is mainly due to loss of baseline psychological support.

\section{Conclusion \& Recommendations:}

Glycemic control is hard to be studied because of the deficiency of HbA1c's readings in most of the patients. COVID-19 lockdown has led to decreased physical activity and unchanged dietary habits among most participants. There were difficulty getting insulin pump supplies because their availability was limited to one company in Khartoum, and the main bridges between the cities in Khartoum state and the interstate crossings were closed. The shortage and high price of diabetes care tools led to a decrease in SMBG among participants. Most of the patients do not follow up regularly with a physician or diabetes educator.

From what were mentioned above we recommend the following:

1. Performing an educational program for the insulin pump users about the importance of follow-up with a physician, exercise performance and maintaining a healthy diet.

2. To encourage the insulin pump users to have a regular follow up with a multi- disciplinary team which includes a physician, a diabetes educator, nutritionist, a psychologist and a social worker.

3. Distribution of insulin pump supplies among Khartoum state cities should be taken seriously. 
4. To insure the availability of diabetes care tools with affordable prices.

\section{Declarations}

\section{Ethics approval and consent to participate:}

Ethical approval was obtained from the ethical committee of the community medicine department, faculty of medicine, University of Khartoum. Both verbal and written consents to participate and to publish this information were obtained from the patients.

\section{Consent to publish:}

Consent for publication was obtained from all patients and authors.

\section{Availability of data and materials:}

The datasets used and $\backslash$ or analyzed during the current study are available from the corresponding author on reasonable request.

\section{Competing interests:}

The authors have no conflict of interest to declare.

\section{Funding:}

The authors received no funding for this work.

\section{Authors' contributions}

All authors participated in planning the study, data collection, analysis and draft writing \& revision.

\section{Acknowledgment:}

Not applicable.

\section{References}

1. Weiss SR, Leibowitz and JL. Coronavirus Pathogenesis. 2020.

2. World Health Organization (WHO). World Health Organization Press Conference The World Health Organization (WHO) Has Officially Named the Disease Caused by the Novel Coronavirus as COVID-19 [Internet]. 2020. Available from: https://www.who.int/emergencies/diseases/novel-coronavirus-2019.

3. Affairs UO for the $\mathrm{C}$ of H. Sudan: COVID-19 Situation Overview \& Response (20 December 2020) [Internet]. 2020. Available from: sudan-covid-19-situation-overview-response-10-november-2020 @ reliefweb.int. 
4. Diabetes Fl. What-Is-Diabetes @ Www.Idf.Org. 2015.

5. Diabetes FI. Diabetes complications [Internet]. 2020. Available from: https://www.idf.org/aboutdiabetes/complications.html.

6. Syndrome M, Negera GZ, Weldegebriel B, Fekadu G. Acute Complications of Diabetes and its Predictors among Adult Diabetic Patients at Jimma Medical Center, Southwest Ethiopia. 2020; 1237-42.

7. No Title [Internet]. Available from: https://diabetesatlas.org/upload/resources/material/20200302_13335 1_IDFATLAS9e-final-web.pdf.

8. Wenzel J. Insulin pump therapy. JEMS. 2015;40(9):40-3.

9. Banerjee M, Chakraborty S, Pal R. Diabetes self-management amid COVID-19 pandemic. Diabetes Metab Syndr Clin Res Rev [Internet]. 2020; 14(4):351-4. Available from: https://doi.org/10.1016/j.dsx.2020.04.013.

10. Magliah SF, Zarif HA, Althubaiti A, Sabban MF. Since January 2020 Elsevier has created a COVID-19 resource centre with free information in English and Mandarin on the novel coronavirus COVID- 19. The COVID-19 resource centre is hosted on Elsevier Connect, the company 's public news and information. 2020 ;(January).

11. Stephens E. Insulin Therapy in Type 1 Diabetes. Med Clin North Am [Internet]. 2015;99(1):145-56. Available from: http://dx.doi.org/10.1016/j.mcna.2014.08.016.

12. Defronzo RA. From the triumvirate to the ominous octet: A new paradigm for the treatment of type 2 diabetes mellitus. Diabetes. 2009;58(4):773-95.

13. Magliah SF, Zarif HA, Althubaiti A, Sabban MF. Since January 2020 Elsevier has created a COVID-19 resource centre with free information in English and Mandarin on the novel coronavirus COVID- 19. The COVID-19 resource centre is hosted on Elsevier Connect, the company 's public news and information. 2020;(January).

14. Shah K, Tiwaskar M, Chawla P, Kale M, Deshmane R. Diabetes \& Metabolic Syndrome: Clinical Research \& Reviews Hypoglycemia at the time of Covid-19 pandemic. Diabetes Metab Syndr Clin Res Rev [Internet]. 2020;14(5):1143-6. Available from: https://doi.org/10.1016/j.dsx.2020.07.003.

15. Odeh R, Gharaibeh L, Daher A, Kussad S, Alassaf A. Caring for a child with type 1 diabetes during COVID-19 lockdown in a developing country: Challenges and parents ' perspectives on the use of telemedicine. Diabetes Res Clin Pract [Internet]. 2020;168:108393. Available from: https://doi.org/10.1016/j.diabres.2020.108393.

16. Aragona M, Rodia C, Bertolotto A, Campi F, Coppelli A, Giannarelli R, et al. Type 1 diabetes and COVID19: the "Lockdown effect" Diabetes Res Clin Pract[Internet]. 2020;108468. Available from: https://doi.org/10.1016/j.diabres.2020.108468.

17. Grabia M, Zukowska RM-, Pu A, Bielecka J, Nowakowski P, Gromkowska-k K, et al. nutrients The Nutritional and Health E ff ects of the COVID-19 Pandemic on Patients with Diabetes Mellitus. 2020; (June):1-15. 
18. Christoforidis A, Kavoura E, Nemtsa A, Pappa K, Dimitriadou M. Coronavirus lockdown effect on type 1 diabetes management on children wearing insulin pump equipped with continuous glucose monitoring system. Diabetes Res Clin Pract [Internet]. 2020.;166:108307. Available from: https://doi.org/10.1016/j.diabres.2020.108307.

19. Boscari F, Ferretto S, Uliana A, Avogaro A, Bruttomesso D. Efficacy of telemedicine for persons with type 1 diabetes during Covid19 lockdown. Nutr Diabetes [Internet]. 2021;11(1):1-5. Available from: http://dx.doi.org/10.1038/s41387-020-00147-8.

20. Tornese G, Ceconi V, Monasta L, Carletti C, Faleschini E, Barbi E. Glycemic Control in Type 1 Diabetes Mellitus During COVID-19 Quarantine and the Role of In-Home Physical Activity. Diabetes Technol Ther. 2020;22(6):462-7.

21. Misra A, Bloomgarden Z. Diabetes during the COVID-19 pandemic: A global call to reconnect with patients and emphasize lifestyle changes and optimize glycemic and blood pressure control. $\mathrm{J}$ Diabetes. 2020;12(7):556-7.

22. Grabowski D, Overgaard M, Meldgaard J, Johansen LB, Willaing I. Disrupted Self-Management and Adaption to New Diabetes Routines: A Qualitative Study of How People with Diabetes Managed Their Illness during the COVID-19 Lockdown. 2021;1- 15.

23. Ghosh A, Arora B, Gupta R, Anoop S, Misra A. Effects of nationwide lockdown during COVID-19 epidemic on lifestyle and other medical issues of patients with type 2 diabetes in north India. Diabetes Metab Syndr Clin Res Rev [Internet]. 2020;14(5):917-20. Available from: https://doi.org/10.1016/j.dsx.2020.05.044.

24. Knott-torcal C, Matilla-escalante DC. COVID-19 Lockdown and Changes of the Dietary Pattern and Physical Activity Habits in a Cohort of Patients with Type 2 Diabetes Mellitus.

25. Deeb A, Abu-Awad S, Abood S, El-Abiary M, Al-Jubeh J, Yousef H, et al. Important determinants of diabetes control in insulin pump therapy in patients with type 1 diabetes mellitus. Diabetes Technol Ther. 2015;17(3):166-70.

26. Abdelgadir M, Elbagir M, Eltom M, Berne $C$. The influence of glucose self-monitoring on glycaemic control in patients with diabetes mellitus in Sudan. Diabetes Res Clin Pract. 2006;74(1):90-4.

27. Pal R, Yadav U, Verma A, Bhadada SK. Awareness regarding COVID-19 and problems being faced by young adults with type 1 diabetes mellitus amid nationwide lockdown in India: A qualitative interview study. Prim Care Diabetes [Internet]. 2021;15(1):10-5. Available from: https://doi.org/10.1016/j.pcd.2020.07.001.

28. Elrayah-Eliadarous HA, Östenson CG, Eltom M, Johansson P, Sparring V, Wahlström R. Economic and social impact of diabetes mellitus in a low-income country: A case-control study in Sudan. $J$ Diabetes. 2017;9(12):1082-90.

29. Mandil S, Consultant E, Informatics H, Organisation WH. Proposals for a Ghana Health Strategy Proposals for a Ghana eHealth Strategy. 2005;(May):1-61.

30. Singhai K, Swami MK, Nebhinani N, Rastogi A, Jude E. Psychological adaptive difficulties and their management during COVID-19 pandemic in people with diabetes mellitus. Diabetes Metab Syndr Clin 
Res Rev [Internet]. 2020;14(6):1603-5. Available from: https://doi.org/10.1016/j.dsx.2020.08.025.

\section{Tables}

Table 1: Age data for Sudanese insulin pump users, Sudan ( $\mathrm{N}=22)$.

\begin{tabular}{ll} 
Age group & $\begin{array}{l}\text { Descriptive statistics }(\mathrm{N}=22, \\
\%)\end{array}$ \\
\hline $\mathbf{5 - 2 5}$ years & $15(68.1 \%)$ \\
\hline 26-55 years & $3(13.6 \%)$ \\
\hline 56-80years & $4(18.1 \%)$
\end{tabular}


Table 2

Reported self-management behavioral changes during the lockdown compared with before the lockdown

\begin{tabular}{|c|c|c|c|c|c|}
\hline Behavior & $\begin{array}{l}\text { Greatly } \\
\text { decreased }\end{array}$ & $\begin{array}{l}\text { Somewhat } \\
\text { decreased }\end{array}$ & No change & $\begin{array}{l}\text { Somewhat } \\
\text { increased }\end{array}$ & $\begin{array}{l}\text { Greatly } \\
\text { increase } \\
\text { d }\end{array}$ \\
\hline $\begin{array}{l}\text { Maintaining } \\
\text { physical } \\
\text { activity }\end{array}$ & $6(27.3)$ & $4(18.2)$ & $9(40.9)$ & 3 (13.6) & $0(0)$ \\
\hline $\begin{array}{l}\text { Ability to follow } \\
\text { healthy diet }\end{array}$ & 3 (13.6) & $4(18.2)$ & $11(50.0)$ & $1(4.5)$ & $3(13.6)$ \\
\hline $\begin{array}{l}\text { Experiencing } \\
\text { symptoms of } \\
\text { hyperglycemia }\end{array}$ & $2(9.1)$ & $2(9.1)$ & $10(45.5)$ & $5(22.7)$ & $3(13.6)$ \\
\hline $\begin{array}{l}\text { Experiencing } \\
\text { symptoms of } \\
\text { hypoglycemia }\end{array}$ & $1(2.4)$ & $1(2.4)$ & $16(72.7)$ & $3(13.6)$ & $1(2.4)$ \\
\hline $\begin{array}{l}\text { Adherence to } \\
\text { carbohydrate } \\
\text { counting }\end{array}$ & $3(13.6)$ & $1(4.5)$ & $14(63.6)$ & $2(9.1)$ & $2(9.1)$ \\
\hline $\begin{array}{l}\text { Adherence to Bolus } \\
\text { Wizard during }\end{array}$ & $1(4.5)$ & $1(4.5)$ & $15(68.2)$ & 3 (13.6) & $2(9.1)$ \\
\hline mealtime & & & & & \\
\hline $\begin{array}{l}\text { Adherence to Bolus } \\
\text { Wizard for } \\
\text { correction dose for } \\
\text { hyperglycemia }\end{array}$ & $1(4.5)$ & $2(9.1)$ & $15(68.2)$ & $4(18.2)$ & $0(0)$ \\
\hline $\begin{array}{l}\text { For glucometer } \\
\text { users, adherence to } \\
\text { SMBG } 4 \text { times } \\
\text { per day }\end{array}$ & $5(22.7)$ & $2(9.1)$ & $9(40.9)$ & $5(22.7)$ & $1(4.5)$ \\
\hline
\end{tabular}

